\title{
Exercise performance and symptoms in lowlanders with COPD ascending to moderate altitude: randomized trial
}

This article was published in the following Dove Press journal: International Journal of COPD

\author{
Michael Furian ${ }^{1, *}$ \\ Deborah Flueck',* \\ Tsogyal D Latshang' \\ Philipp M Scheiwiller' \\ Sebastian Daniel Segitz' \\ Séverine Mueller-Mottet' \\ Christian Murer' \\ Adrian Steiner ${ }^{\prime}$ \\ Silvia Ulrich' \\ Thomas Rothe ${ }^{2}$ \\ Malcolm Kohler' \\ Konrad E Bloch' \\ 'Department of Respiratory Medicine, \\ University Hospital of Zurich, Zurich, \\ Switzerland; ${ }^{2}$ Zuercher RehaZentrum \\ Davos, Davos Clavadel, Switzerland \\ *These authors contributed equally \\ to this work
}

Correspondence: Konrad E Bloch Department of Respiratory Medicine, University Hospital of Zurich,

Raemistrasse 100, 8091 Zurich,

Switzerland

Tel +4I 442553828

Fax +4| 44255445 I

Email konrad.bloch@usz.ch
Objective: To evaluate the effects of altitude travel on exercise performance and symptoms in lowlanders with COPD.

Design: Randomized crossover trial.

Setting: University Hospital Zurich (490 m), research facility in mountain villages, Davos Clavadel (1,650 m) and Davos Jakobshorn (2,590 m).

Participants: Forty COPD patients, Global Initiative for Obstructive Lung Disease (GOLD) grade $2-3$, living below $800 \mathrm{~m}$, median (quartiles) age 67 y $(60 ; 69)$, forced expiratory volume in 1 second $57 \%$ predicted $(49 ; 70)$.

Intervention: Two-day sojourns at $490 \mathrm{~m}, 1,650 \mathrm{~m}$, and 2,590 $\mathrm{m}$ in randomized order.

Outcome measures: Six-minute walk distance (6MWD), cardiopulmonary exercise tests, symptoms, and other health effects.

Results: At $490 \mathrm{~m}$, days 1 and 2, median (quartiles) 6MWD were $558 \mathrm{~m}(477 ; 587)$ and $577 \mathrm{~m}$ $(531 ; 629)$. At 2,590 m, days 1 and 2, mean changes in 6MWD from corresponding day at $490 \mathrm{~m}$ were $-41 \mathrm{~m}(95 \% \mathrm{CI}-51$ to -31$)$ and $-40 \mathrm{~m}(-53$ to -27$), \mathrm{n}=40, P<0.05$, both changes. At $1,650 \mathrm{~m}$, day $1,6 \mathrm{MWD}$ had changed by $-22 \mathrm{~m}$ ( -32 to -13$)$, maximal oxygen uptake during bicycle exercise by $-7 \%$ ( -13 to 0 ) vs $490 \mathrm{~m}, P<0.05$, both changes. At $490 \mathrm{~m}, 1,650 \mathrm{~m}$, and 2,590 m, day 1 , resting $\mathrm{PaO}_{2}$ were $9.0(8.4 ; 9.4), 8.1(7.5 ; 8.6)$, and $6.8(6.3 ; 7.4) \mathrm{kPa}$, respectively, $P<0.05$ higher altitudes vs $490 \mathrm{~m}$. While staying at higher altitudes, nine patients (24\%) experienced symptoms or adverse health effects requiring oxygen therapy or relocation to lower altitude.

Conclusion: During sojourns at 1,650 $\mathrm{m}$ and 2,590 m, lowlanders with moderate to severe COPD experienced a mild reduction in exercise performance and nearly one quarter required oxygen therapy or descent to lower altitude because of adverse health effects. The findings may help to counsel COPD patients planning altitude travel.

Registration: ClinicalTrials.gov: NCT01875133

Keywords: CPET, cardiopulmonary exercise testing, acute mountain sickness, hypoxia, adverse health effects, dyspnea, altitude illness, arterial blood gas analysis, pulmonary function

\section{Introduction}

COPD is characterized by chronic airflow obstruction related to airway inflammation, remodeling, and parenchymal destruction of the lung. ${ }^{1}$ This causes dyspnea, exercise limitation, and an impaired quality of life. Worldwide, more than 200 million tourists are estimated to visit altitudes over $1,500 \mathrm{~m}$ each year. ${ }^{2}$ Among them, many patients with COPD are expected to experience adverse health effects including acute mountain sickness, ${ }^{3}$ excessive dyspnea, and impairment of exercise performance during everyday activities when exposed to hypobaric hypoxia during altitude sojourns. However, 
whether and to which extent impaired pulmonary gas exchange, reduced muscle strength, and cardiovascular and other limitations affect well-being and physical performance in COPD patients traveling to high altitude has not been extensively studied. In a recent physiological investigation, we observed a reduction of submaximal constant load bicycle exercise by about one half due to systemic and cerebral hypoxemia in a group of COPD patients at 2,590 m compared with the performance at their low altitude residence. ${ }^{4}$ To provide a scientific basis to counsel COPD patients planning altitude sojourns, the current study evaluated the effect of travel to altitudes of 1,650 and 2,590 $\mathrm{m}$ for a total of 4 days on exercise performance, general well-being, and several other outcomes in lowlanders with moderate to severe COPD.

\section{Methods}

\section{Study design and setting}

This randomized crossover trial evaluated the effect of a 4-day sojourn at moderate altitude on exercise performance, symptoms, and several physiological outcomes in patients with stable COPD, Global Initiative for Obstructive Lung Disease (GOLD) grades 2-3, living below $800 \mathrm{~m}$. The studies were performed from June to August 2013 in Zurich (490 m, 1,608 ft, barometric pressure [PB] 719 Torr) and in Swiss alpine villages, Davos Clavadel $(1,650 \mathrm{~m}, 5,413 \mathrm{ft}, \mathrm{PB} 628$ Torr) and Davos Jakobshorn (2,590 m, 8,497 ft, PB 562 Torr). Participants spent 2 days at each study location, in random order, to undergo outcome assessments. Some physiological outcomes evaluating gas exchange, cerebral blood flow, and cerebral and muscle tissue oxygenation as a part of the current trial have been reported recently. ${ }^{4}$ Apart from baseline characteristics of study participants, the data presented here have not been published except previously in abstract form. The study was approved by the Cantonal Ethics Committee of Zurich (EK-2013-0088), subjects gave written informed consent, and the trial is registered at www.ClinicalTrials. gov: NCT01875133.

\section{Participants}

Subjects with stable COPD, GOLD grade 2-3, diagnosed according to the GOLD guidelines (forced expiratory volume in 1 second $\left[\mathrm{FEV}_{1}\right] /$ forced vital capacity [FVC] ratio $<0.7, \mathrm{FEV}_{1}$ between $30 \%$ and $80 \%$ predicted), aged 18 to 75 years, both sexes, living below $800 \mathrm{~m}$, were invited to participate. Subjects with very severe COPD $\left(\mathrm{FEV}_{1}<30 \%\right.$ predicted), respiratory failure at lowland $\left(\mathrm{PaO}_{2}<7.3 \mathrm{kPa}\right.$ or $\mathrm{PaCO}_{2}>6.0 \mathrm{kPa}$ ), or those with known previous intolerance of altitude 2,600 m or lower, a history of sleep apnea syndrome, or more than mild or inadequately controlled cardiovascular disease were excluded. Patients having traveled to altitudes $>1,500 \mathrm{~m}$ for $>2$ days within 4 weeks prior to the study were also excluded.

\section{Randomization and intervention}

Using a balanced block design, participants were randomized to one of the following four sequences of altitude exposure with sojourns of 2 days at each location: Group A 490/1,650/2,590 m; Group B 490/2,590/1,650 m; Group C 1,650/2,590/490 m; Group D 2,590/1,650/490 m. Participants traveled by train and car between Zurich and Davos Clavadel and by cable car between Davos Clavadel and Davos Jakobshorn.

As a safety precaution, the protocol required that any patient with intolerable discomfort (according to the patient's own subjective assessment), symptoms or signs of relevant intercurrent illness, such as a COPD exacerbation, new onset or unstable cardiovascular disease including uncontrolled hypertension (systolic and/or diastolic blood pressure $>220$ and/ or $>110 \mathrm{mmHg}$ ), neurological impairment, gastrointestinal symptoms requiring treatment, or severe hypoxemia (arterial oxygen saturation $<80 \%$ for $>30$ minutes) were withdrawn from the study, treated with oxygen and other measures as appropriate, and transported to low altitude. Maximal bicycle exercise tests to exhaustion were performed at $490 \mathrm{~m}$ and 1,650 $\mathrm{m}$, but for safety reasons, not at 2,590 m. Patients were asked to continue their regular medication during the study.

\section{Assessments}

Exercise tests, pulmonary function, and arterial blood gas analysis

Six-minute walk tests with monitoring of pulse oximetry $\left(\mathrm{SpO}_{2}\right)$ were performed. ${ }^{5}$

Lung function studies including spirometry, body plethysmography (only at 490 and 2,590 m due to logistical constraints), diffusing capacity (Bodystik ${ }^{\mathrm{TM}}$ and Diffustik ${ }^{\mathrm{TM}}$, Geratherm Respiratory GmbH, Bad Kissingen, Germany), and nasal sniff inspiratory pressure (Morgan P max, Morgan Medical Ltd., Gillingham, UK) were performed 15 minutes after inhalation of a short-acting bronchodilator. ${ }^{6,7}$ Pulmonary volumes and flows were expressed in body temperature, pressure, and saturated conditions. Diffusing capacity was measured by the single-breath technique. To allow for convenient comparisons between values measured at $490 \mathrm{~m}$, 2,590 m, and predicted values for sea level, values measured 
at 2,590 m were corrected for the lower PB at altitude by transforming the equation recommended to predict values at high altitude: ${ }^{8}$

$$
\begin{aligned}
{\left[\mathrm{DLCO}_{\text {altitude }}=\right.} & \left.\mathrm{DLCO}_{\text {sea level }} /\left(1+0.00031 *\left[\mathrm{PI}, \mathrm{O}_{2}-150\right]\right)\right], \\
& \text { and solving for } \mathrm{DLCO}_{\text {sea level }}, \\
{\left[\mathrm{DLCO}_{\text {sea level }}=\right.} & \left.\mathrm{DLCO}_{2,590 \mathrm{~m}} *\left(1+0.00031 *\left[\mathrm{PI}, \mathrm{O}_{2}-150\right]\right)\right], \\
& \text { whereas PI, } \mathrm{O}_{2} \text { at } 2,590 \mathrm{~m} \text { corresponds to } \\
& 108 \mathrm{mmHg} .
\end{aligned}
$$

Cardiopulmonary cycle exercise tests were performed with a progressive ramp protocol to exhaustion ${ }^{9}$ at $490 \mathrm{~m}$ and $1,650 \mathrm{~m}$. The target duration of the exercise test at $490 \mathrm{~m}$ was 8-12 minutes, and the slope (ie, increase in watts per minute) was selected accordingly, based on the individually predicted maximal work rate $(W \max )$. For each individual, an identical ramp protocol was applied at $490 \mathrm{~m}$ and $1,650 \mathrm{~m}$. Ventilation, gas exchange, oxygen saturation, and electrocardiogram were recorded breath by breath (Ergostik ${ }^{\mathrm{TM}}$, Geratherm Respiratory $\mathrm{GmbH}$ ). Radial artery blood was drawn at rest and during maximal exercise and analyzed immediately (RAPIDPOINT 405, Siemens Healthcare Diagnostics GmbH, Zurich, Switzerland). Maximal physiologic variables of exercise tests were defined as mean values during the final 30 seconds of maximal exercise. Patients indicated the perceived exertion on the Borg CR10 scale. ${ }^{10}$

\section{Clinical examination, evaluation of acute mountain sickness (AMS), and dyspnea}

A complete medical history was obtained. Physical examination included weight, height, blood pressure, pulse rate, and $\mathrm{SpO}_{2}$. Dyspnea was assessed by the modified Medical Research Council dyspnea score. ${ }^{11}$ AMS was assessed in the morning and evening by the Environmental Symptoms Questionnaire cerebral score (AMSc) comprising 11 questions on AMS symptoms rated from 0 (not at all) to 5 (extreme). The weighted sum of responses ranges from 0 to 5 . Scores $\geq 0.7$ are considered to reflect clinically relevant AMS. ${ }^{12}$

\section{Outcomes}

The primary outcome was the change in the 6-minute walk distance (6MWD). Secondary outcomes were the oxygen saturation by $\mathrm{SpO}_{2}$, heart rate, lung function, arterial blood gases, and measures derived from cardiopulmonary exercise testing.

\section{Sample size}

Sample size estimation indicated that at least 36 participants were required to detect a minimally important difference in the $6 \mathrm{MWD}$ of $30 \mathrm{~m}$ (SD $55 \mathrm{~m}$ ) with a power of $80 \%$, alpha $0.05 .{ }^{13}$ To account for dropouts, 40 participants were included.

\section{Blinding}

Investigators analyzing the data were blinded to altitude and altitude exposure sequence.

\section{Statistical analysis}

Due to non-normal distribution of the majority of the data, all variables were summarized by medians and quartiles. Overall effects were evaluated by Friedman ANOVA, and significant findings were further analyzed by post hoc analyses using Wilcoxon matched pairs tests. Effects of altitude exposure were evaluated by computing mean differences in outcomes with $95 \%$ CIs. The primary outcome was analyzed according to the intention-to-treat principle with missing data replaced by multiple imputations applying a multivariable regression model with baseline variables as independent predictors. Secondary outcomes were analyzed according to the perprotocol principle on all available data. Regression analyses were used to separately assess the effect of altitude $(1,650 \mathrm{~m}$ and 2,590 $\mathrm{m}$ vs $490 \mathrm{~m}$ ) on the 6MWD while controlling for baseline characteristics and potential confounders. Age, sex, and all predictor variables for which univariate analysis revealed an association with $P<0.2$ were entered into a subsequent multivariable model. A probability of $P<0.05$ was considered as statistically significant.

\section{Results}

The study participant flow is shown in Figure 1. Of 191 screened subjects, 139 refused to participate and 12 met exclusion criteria. Thus, 40 subjects were included and randomized and their primary outcome (6MWD) was analyzed according to the intention-to-treat principle. One patient each in groups $\mathrm{A}$ to $\mathrm{C}$ and two in group $\mathrm{D}$ required nocturnal supplemental oxygen because of severe hypoxemia (as defined per protocol by a value of $\mathrm{SpO}_{2}<80 \%$ for $\geq 30$ minutes) or dyspnea. These subjects felt well thereafter and remained at altitude but were excluded from exercise tests on the next day. Two subjects withdrew informed consent after baseline examination in Zurich and one refused to ascend to 2,590 $\mathrm{m}$ because of insomnia at $1,650 \mathrm{~m}$. Thus, the per-protocol group consisted of 32 participants (Table 1). The age of patients ranged from 51 to $74 \mathrm{y}, 25 \%$ were current smokers, and the median $\mathrm{FEV}_{1}$ was $59 \%$ predicted. The most prevalent comorbidities were cardiovascular diseases. 


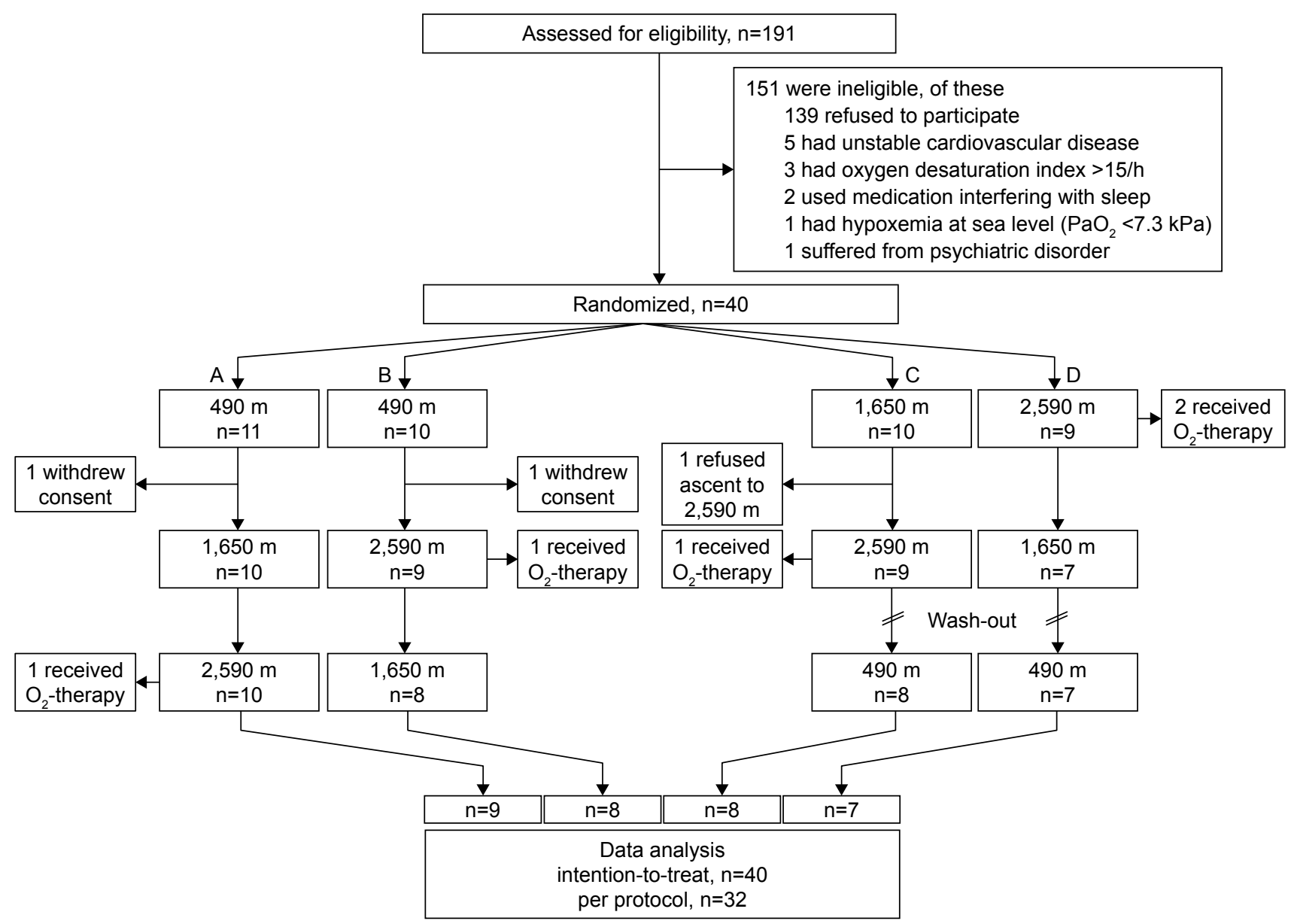

Figure I Patient flow.

Notes: Of 191 eligible subjects, 40 were randomized into one of the four altitude exposure sequences (A-D) and included in the intention-to-treat analysis. Data from 32 subjects were included in the per-protocol analysis.

The majority of participants (81\%) used regular inhaled $\beta$-adrenergics or anticholinergics and $56 \%$ used inhaled glucocorticoids (Table 1).

Several participants experienced altitude-related adverse health effects. In addition to those mentioned above who were withdrawn because of severe hypoxemia, dyspnea, or other discomfort, patients had (on average) mild symptoms of AMS that were most pronounced on the first day at 2,590 m (Table 2). The incidence of clinically relevant AMS (AMSc score $\geq 0.7$ ) on the first and second day at $1,650 \mathrm{~m}$ was $3 \%$ ( 1 out of 38 ) and $0 \%$, and on the first and second day at $2,590 \mathrm{~m}$ was $5 \%$ (2 out of 38 ) and $0 \%$ in patients ascending to higher altitudes. The combined incidence of any altituderelated adverse health effect during the 4 days at altitude was $24 \%$ ( 9 out of 38 ).

\section{Six-minute walk tests, pulmonary function, and arterial blood gases}

The 6MWD and $\mathrm{SpO}_{2}$ at the beginning and end of the 6-minute walk test were significantly reduced at $1,650 \mathrm{~m}$ and 2,590 m compared with those at $490 \mathrm{~m}$, and the perceived dyspnea at the end of the 6MWD was greater at higher altitudes compared with values at $490 \mathrm{~m}$ (Table 2 and Figure 2).

Univariable regression analysis with the change in the 6MWD from $490 \mathrm{~m}$ baseline as the dependent variable revealed that altitude, second vs first day at altitude, the $6 \mathrm{MWD}, \mathrm{FEV}_{1}$, and DLCO at $490 \mathrm{~m}$ were significant predictors. In a multivariable analysis, maintaining age, sex, and variables with $P<0.2$ in univariable analysis in the model, significant independent predictors for the 6MWD were altitude $1,650 \mathrm{~m}$ (predicted mean change $-17 \mathrm{~m}[95 \%$ $\mathrm{CI}-27$ to $-6 \mathrm{~m}], P=0.001$ ) and $2,590 \mathrm{~m}$ (predicted mean change $-37 \mathrm{~m}[95 \% \mathrm{CI}-47$ to $-27 \mathrm{~m}], P<0.001)$. Additional independent predictors were the baseline value of the 6MWD $(+0.8 \mathrm{~m}[+0.7$ to +0.9$], P<0.001)$ and $\mathrm{FEV}_{1} \%$ predicted at $490 \mathrm{~m}(+0.9 \mathrm{~m}[+0.1$ to +1.7$], P=0.029)$, while age $(P=0.866)$, sex $(P=0.333)$, and DLCO at $490 \mathrm{~m}(P=0.188)$ were not.

Spirometry revealed no significant changes in FVC and $\mathrm{FEV}_{1}$ (in liters) nor in their ratio over the course of the study 
Table I Characteristics of patients

\begin{tabular}{|c|c|}
\hline Characteristic & At baseline \\
\hline \multicolumn{2}{|l|}{ Demographics and clinical characteristics } \\
\hline $\mathrm{n},($ men/women) & $32(19 / 13)$ \\
\hline Age, y & $67(60 ; 70)$ \\
\hline Current smokers, n (\%) & $8(25)$ \\
\hline Smoking, pack-years & $43(20 ; 69)$ \\
\hline $\mathrm{FEV}_{1}, \%$ predicted (postbronchodilator) & $59(5 I ; 7 I)$ \\
\hline GOLD grade 2, n (\%) & $20(63)$ \\
\hline GOLD grade 3, n (\%) & $12(37)$ \\
\hline Body mass index, $\mathrm{kg} / \mathrm{m}^{2}$ & $27.1(22.2 ; 29.2)$ \\
\hline mMRC score & $1.0(1.0 ; 1.5)$ \\
\hline mMRC score $\geq 2, \mathrm{n}(\%)$ & $8(25)$ \\
\hline \multicolumn{2}{|l|}{ Comorbidities, n patients (\%) } \\
\hline Arterial hypertension & $19(59)$ \\
\hline Coronary artery disease and other & $8(25)$ \\
\hline \multicolumn{2}{|l|}{ cardiovascular diseases } \\
\hline Diabetes mellitus & $2(6)$ \\
\hline Depression & $8(25)$ \\
\hline Previous pulmonary embolism & $2(6)$ \\
\hline Dyslipidemia & $9(28)$ \\
\hline \multicolumn{2}{|l|}{ Medication, $\mathrm{n}$ patients (\%) } \\
\hline Inhalation of topical corticosteroids & $18(56)$ \\
\hline Inhalation of $\beta$-adrenergics & $26(81)$ \\
\hline Inhalation of anticholinergics & $26(8 I)$ \\
\hline Roflumilast & I (3) \\
\hline Diuretics & $7(22)$ \\
\hline ACE-inhibitor or AT2 antagonist & $17(53)$ \\
\hline$\beta$-blocker & $8(25)$ \\
\hline Calcium channel blocker & $6(19)$ \\
\hline Lipid-lowering therapy & $7(22)$ \\
\hline Antidiabetics & $2(6)$ \\
\hline Antidepressants & $7(22)$ \\
\hline Theophylline & I (3) \\
\hline Antiplatelet therapy & $7(22)$ \\
\hline Oral anticoagulation & $3(9)$ \\
\hline Antiarrhythmic therapy & I (3) \\
\hline
\end{tabular}

Note: Values presented as median (quartiles) unless indicated otherwise.

Abbreviations: ACE, angiotensin-converting enzyme; AT2, angiotensin II receptor; $\mathrm{FEV}_{\text {l, }}$, forced expiratory volume in I second; GOLD, global initiative for chronic obstructive lung disease; mMRC, modified Medical Research Council dyspnea score; Pack-years, sum of years smoked a packet of cigarettes per day. at the different altitudes (Table 3). FVC (in \% predicted) tended to be minimally greater at $1,650 \mathrm{~m}$ compared with other altitudes. Static lung volumes (total lung capacity, residual volume) were not different at $2,590 \mathrm{~m}$ vs $490 \mathrm{~m}$. Peak expiratory flow improved significantly with increasing altitude, and correspondingly, airway resistance was reduced at $2,590 \mathrm{~m}$ vs $490 \mathrm{~m}$. There was a slight but statistically significant reduction in the DLCO corrected for hemoglobin and for the reduced PB at 2,590 $\mathrm{m}$.

The arterial blood gas analysis revealed a mild to moderate hypoxemia that increased with altitude (Figure 2, Table 4). The alveolar-arterial $\mathrm{PO}_{2}$ gradient was elevated at $490 \mathrm{~m}$ and decreased slightly at higher altitudes but remained elevated. According to inclusion criteria, patients were normocapnic at $490 \mathrm{~m}$ and their $\mathrm{PaCO}_{2}$ was slightly reduced at higher altitudes with an associated increase in $\mathrm{pH}$.

\section{Cardiopulmonary exercise tests}

Compared with $490 \mathrm{~m}$, endurance time, $W$ max, and maximal oxygen uptake $\left(\mathrm{V}^{\prime} \mathrm{O}_{2}\right.$ normalized for weight) were all significantly reduced at $1,650 \mathrm{~m}$. The reduction in endurance time and thus $W \max$ was $-7 \%$ ( $95 \% \mathrm{CI}-13$ to $0, P<0.01)$. The impairment in exercise performance at $1,650 \mathrm{~m}$ was associated with a reduced $\mathrm{PaO}_{2}, \mathrm{SaO}_{2}$, and alveolar-arterial $\mathrm{PO}_{2}$ gradient during maximal exercise; in addition, there was a lower $\mathrm{PaCO}_{2}$ and increased ventilatory equivalents for $\mathrm{O}_{2}$ uptake and $\mathrm{CO}_{2}$ output $\left(\mathrm{V}^{\prime} \mathrm{E} / \mathrm{O}_{2}\right.$ and $\left.\mathrm{V}^{\prime} \mathrm{E} / \mathrm{CO}_{2}\right)$ compared with $490 \mathrm{~m}$. Subjective perception of dyspnea and leg fatigue were similar at low and high altitude (Table 5).

\section{Discussion}

The results of the current randomized trial show that patients with moderate to severe COPD living below $800 \mathrm{~m}$

Table 2 Six-minute walk test and clinical evaluation

\begin{tabular}{|c|c|c|c|c|c|c|c|}
\hline & \multicolumn{2}{|l|}{$490 \mathrm{~m}$} & \multicolumn{2}{|l|}{$1,650 \mathrm{~m}$} & \multicolumn{2}{|l|}{$2,590 \mathrm{~m}$} & \multirow[t]{2}{*}{$P$-value } \\
\hline & First day & Second day & First day & Second day & First day & Second day & \\
\hline $\begin{array}{l}\text { 6-minute walk } \\
\text { distance, } \mathrm{m}\end{array}$ & $534 \pm 93$ & $547 \pm 93 *$ & $512 \pm 93^{*, \#}$ & $525 \pm 93^{\#, \dagger}$ & $491 \pm 93^{*, \#,+, .+}$ & $504 \pm 93^{\#, \neq, \pi}$ & $<0.001$ \\
\hline $\mathrm{SpO}_{2}$, rest, \% & $94(94 ; 96)$ & $94(93 ; 95)$ & $92^{*, \#}(91 ; 94)$ & $93 * ; *$ (91; 95) & 89 *.\#,+, (88; 9I) & $90^{*, \#,+, \neq}(87 ; 92)$ & $<0.001$ \\
\hline $\mathrm{SpO}_{2}$, end of $6 \mathrm{MWT}, \%$ & $90(84 ; 92)$ & $89(83 ; 92)$ & $84^{* \# \#}(78 ; 87)$ & $85^{*, \#}(77 ; 87)$ & $78^{*, \#,+,+\neq}(73 ; 82)$ & $77^{*, \#,+, \neq}(73 ; 82)$ & $<0.001$ \\
\hline Borg dyspnea & $3.0(2.0 ; 5.0)$ & $3.0(3.0 ; 4.5)$ & $4.0(2.0 ; 4.5)$ & $4.0^{*, \#, \dagger}(3.0 ; 5.5)$ & $3.5(3.0 ; 5.0)$ & $4.0^{* * \#, \dagger}(3.0 ; 6.0)$ & 0.003 \\
\hline Borg leg fatigue & $2.5(2.0 ; 4.0)$ & $3.0(1.0 ; 5.0)$ & $2.5(1.5 ; 4.0)$ & $3.0(1.0 ; 4.0)$ & $2.0(0.8 ; 3.0)$ & $3.0(1.5 ; 3.0)$ & 0.567 \\
\hline mMRC dyspnea score & $\mathrm{I}(0 ; \mathrm{I})$ & $I(I ; I)$ & $I(I ; I)$ & $\mathrm{I}(\mathrm{I} ; \mathrm{I})$ & $I(I ; I)$ & $\mathrm{I}^{\#}(\mathrm{I} ; \mathrm{I})$ & 0.045 \\
\hline $\begin{array}{l}\text { Acute mountain } \\
\text { sickness score }\end{array}$ & $0.00(0.00 ; 0.09)$ & $0.00(0.00 ; 0.00)$ & $0.00(0.00 ; 0.18)$ & $0.00(0.00 ; 0.09)$ & $0.18^{*,+,+, \neq}(0.00 ; 0.35)$ & $0.00^{\pi}(0.00 ; 0.09)$ & $<0.001$ \\
\hline Weight, kg & $77.3(67.9 ; 87.4)$ & $77.3(68.2 ; 87.4)$ & $78.2^{* \#}(66.6 ; 88.6)$ & $78.3^{*, \#}(67.4 ; 87.9)$ & $78.3^{*, \#}(67.9 ; 88.0)$ & $78.6^{*, \#}(67.5 ; 87.9)$ & $<0.001$ \\
\hline
\end{tabular}

Notes: Six-minute walk distance analyzed by the intention-to-treat analysis including all 40 randomized patients, values presented as mean \pm SD. Other outcomes analyzed by the per-protocol approach including 32 patients, values presented as median (quartiles). $P$-values from Friedman ANOVA. $* P<0.05$ vs $490 \mathrm{~m}$ day I, ${ }^{P} P<0.05$ vs $490 \mathrm{~m}$ day 2 , ${ }^{+} P<0.05$ vs $\mathrm{I}, 650 \mathrm{~m}$ day $\mathrm{I},{ }^{\ddagger} P<0.05$ vs $\mathrm{I}, 650 \mathrm{~m}$ day $2,{ }^{\top} P<0.05$ vs $2,590 \mathrm{~m}$ day $\mathrm{I}$.

Abbreviations: 6MWT, 6-minute walk test; mMRC, modified Medical Research Council dyspnea score; $\mathrm{SpO}_{2}$, pulse oximetry. 
6-minute walk distance (6MWD), m

Arterial oxygen saturation at end of GMWD, \%

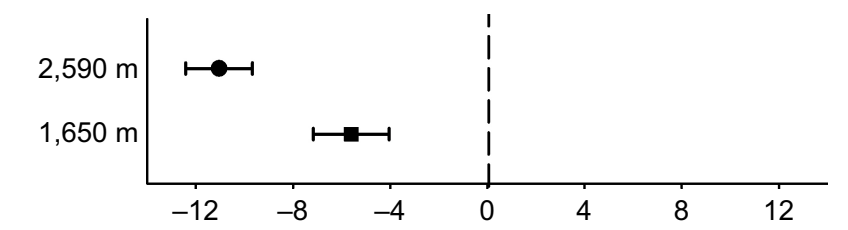

$-11.0(-12.4$ to -9.7$)$

$-5.6(-7.2$ to -4.1$)$

Borg CR10 dyspnea score at end of 6MWD

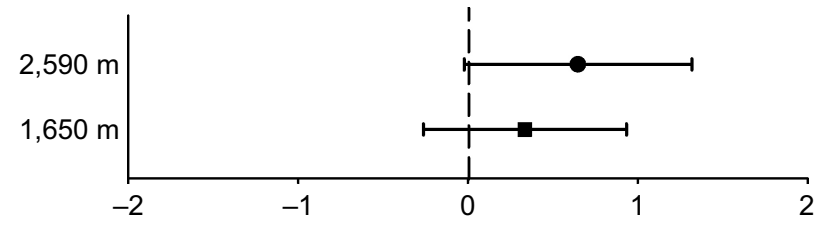

Mean arterial pressure at end of $6 \mathrm{MWD}, \mathrm{mmHg}$

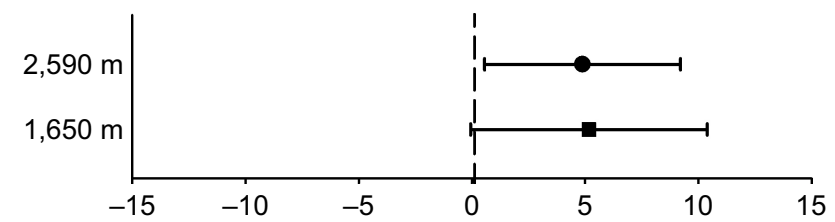

5 (1 to 9 )

$5(-1$ to 10$)$

5

$0.6(-0.0$ to 1.3$)$

$0.3(-0.3$ to 0.9$)$

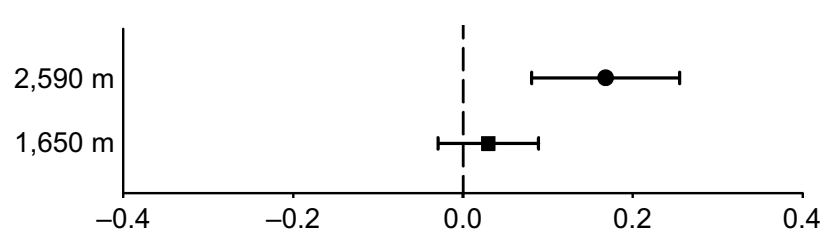

$0.17(0.08$ to 0.26$)$

Acute mountain sickness score

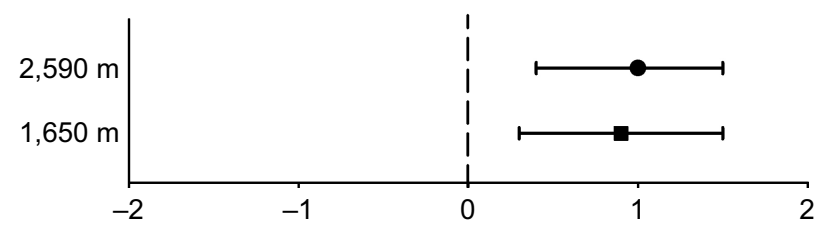

$1.0(0.4$ to 1.5$)$

Weight, kg

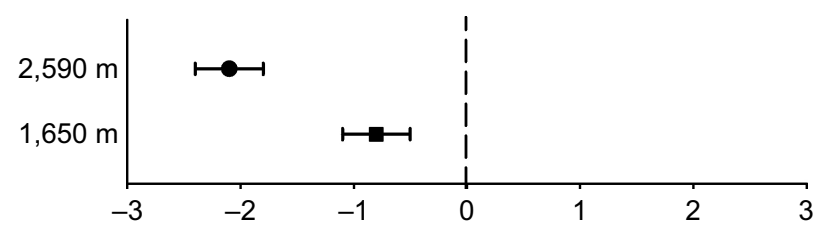

$-2.1(-2.4$ to -1.8$)$ pressure of $\mathrm{O}_{2}, \mathrm{kPa}$

Arterial partial pressure of $\mathrm{CO}_{2}, \mathrm{kPa}$

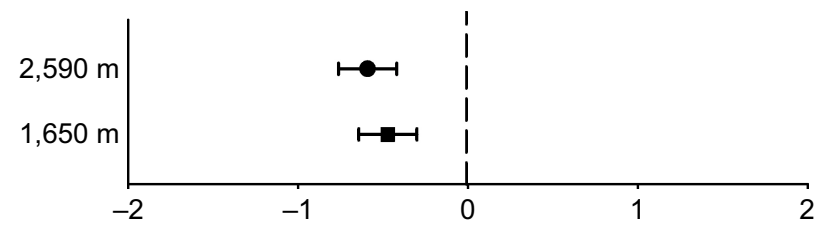

$-0.6(-0.8$ to -0.4$)$

$-0.5(-0.6$ to -0.3$)$

Altitude-induced changes between 1,650 m and 2,590 m compared with $490 \mathrm{~m}$

Figure 2 Altitude-induced changes.

Notes: Dots represent mean differences and horizontal bars the $95 \% \mathrm{Cls}$, values are numerically indicated on the right. Altitude effect is significant when the zero value is not part of the $95 \% \mathrm{Cl}$. 
Table 3 Pulmonary function

\begin{tabular}{|c|c|c|c|c|c|c|c|}
\hline & \multicolumn{2}{|l|}{$490 \mathrm{~m}$} & \multicolumn{2}{|l|}{$1,650 \mathrm{~m}$} & \multicolumn{2}{|l|}{$2,590 \mathrm{~m}$} & \multirow[t]{2}{*}{$P$-value } \\
\hline & First day & Second day & First day & Second day & First day & Second day & \\
\hline FVC, L & $3.3(3.0 ; 3.9)$ & $3.5(3.1 ; 4.2)$ & $3.4(3.1 ; 4.2)$ & $3.4(3.0 ; 3.9)$ & $3.3(3.1 ; 4.1)$ & $3.4(3.2 ; 4.1)$ & 0.199 \\
\hline FVC, \% pred & $92(88 ; 109)$ & $95(90 ; 113)$ & $99 *(89 ; 111)$ & 97 (9l; 107) & $95^{\dagger}(88 ; 105)$ & $94^{\dagger}(88 ; 104)$ & 0.034 \\
\hline $\mathrm{FEV}_{1}, \mathrm{~L}$ & $\mathrm{I} .5(\mathrm{I} .3 ; 2 . \mathrm{I})$ & $1.6(1.4 ; 2.1)$ & $1.7(1.4 ; 2.2)$ & $1.6(1.4 ; 2.1)$ & $\mathrm{I} .5(\mathrm{I} .4 ; 2.2)$ & I.6 (I.4; 2.2) & 0.231 \\
\hline $\mathrm{FEV}_{1}$, \% pred & $59(5 I ; 7 I)$ & $57(52 ; 75)$ & $62(58 ; 73)$ & $63(55 ; 7 I)$ & $57(53 ; 69)$ & $56(54 ; 72)$ & 0.107 \\
\hline $\mathrm{FEV}_{1} / \mathrm{FVC}, \%$ & $5 \mathrm{I}(47 ; 62)$ & $5 \mathrm{I}(47 ; 63)$ & $53(46 ; 61)$ & $53(48 ; 62)$ & $53(46 ; 6 I)$ & $53(45 ; 6 I)$ & 0.283 \\
\hline PEF, L & $4.73(3.96 ; 6.19)$ & $4.73(3.76 ; 6.24)$ & $4.95^{*, \#}(4.08 ; 6.49)$ & $5.20^{* \#}(4.23 ; 6.70)$ & $4.88^{\dagger, \neq}(3.93 ; 6.14)$ & $4.95^{\dagger, \neq}(4.02 ; 6.24)$ & $<0.001$ \\
\hline PEF, \% pred & $68(56 ; 83)$ & $69(55 ; 82)$ & $74^{*, \#}(57 ; 88)$ & $72^{*, \#}(62 ; 91)$ & $7 I^{\dagger, \neq}(57 ; 84)$ & $68^{+, \neq}(57 ; 83)$ & $<0.001$ \\
\hline $\begin{array}{l}\text { DLCO Hb adj, } \\
\mathrm{mmol}^{*} \mathrm{~min}^{-1} \mathrm{kPa}^{-1}\end{array}$ & $4.48(3.65 ; 7.05)$ & $4.52(3.62 ; 7.25)$ & $4.48(3.47 ; 6.75)$ & $4.54(3.46 ; 6.75)$ & $4.38^{*, \#}(3.47 ; 6.60)$ & $4.38 *(3.65 ; 6.60)$ & 0.025 \\
\hline DLCO Hb adj, \% pred & $56(45 ; 76)$ & $57(44 ; 76)$ & $56(44 ; 74)$ & $58(44 ; 75)$ & $52^{*, \#}(45 ; 74)$ & $54 *(45 ; 73)$ & 0.013 \\
\hline TLC, L & $6.8(5.9 ; 7.7)$ & $6.9(6.2 ; 7.7)$ & - & - & $6.8(6.1 ; 7.7)$ & $6.8(6.1 ; 7.8)$ & 0.984 \\
\hline TLC, \% pred & III (99; I22) & $110(100 ; 120)$ & - & - & 110 (100; 122) & III (100; 123) & 0.984 \\
\hline $\mathrm{RV}, \mathrm{L}$ & $3.23(2.72 ; 3.60)$ & $3.38(2.66 ; 3.69)$ & - & - & $3.34(2.86 ; 3.68)$ & $3.21(2.76 ; 3.69)$ & 0.395 \\
\hline RV, \% pred & |34 (I |9; |70) & $139(115 ; 166)$ & - & - & I42 (I2I; I72) & $136(115 ; 168)$ & 0.435 \\
\hline RV/TLC ratio & $47(4 I ; 54)$ & $46(42 ; 55)$ & - & - & $47(4 I ; 55)$ & $46(4 I ; 54)$ & 0.371 \\
\hline Raw total, $\mathrm{kPa}{ }^{*} \mathrm{~s} / \mathrm{L}$ & $0.35(0.26 ; 0.47)$ & $0.35(0.29 ; 0.47)$ & - & - & $0.3 I^{* * \#}(0.24 ; 0.4 I)$ & $0.33^{*, \#}(0.24 ; 0.44)$ & $<0.001$ \\
\hline Raw total, \% pred & II (87; I55) & II7 (95; I55) & - & - & $102^{* \#}(78 ; 135)$ & $110^{*, \#}(80 ; 147)$ & $<0.001$ \\
\hline $\mathrm{SNIP}, \mathrm{cmH}_{2} \mathrm{O}$ & $74(59 ; 104)$ & $78(62 ; 94)$ & $79(66 ; 96)$ & $80(66 ; 101)$ & $76(51 ; 93)$ & $8 I(66 ; 91)$ & 0.536 \\
\hline
\end{tabular}

Notes: Median (quartiles), $\mathrm{n}=32$. P-values computed by Friedman ANOVA for overall effects. $* P<0.05$ vs $490 \mathrm{~m}$ day I, ${ }^{*}<<0.05$ vs $490 \mathrm{~m}$ day 2 , ${ }^{\star P}<0.05 \mathrm{vs} \mathrm{I,650} \mathrm{m}$ day I, $\ddagger P<0.05$ vs $1,650 \mathrm{~m}$ day 2 . DLCO Hb adj is the diffusing capacity adjusted for reduced inspiratory $\mathrm{PO}_{2}$ at altitude and corrected for measured hemoglobin (see Methods). Abbreviations: DLCO, diffusing capacity test; $\mathrm{FEV}_{1}$, forced expiratory volume in I second; FVC, forced vital capacity; PEF, peak expiratory flow; RV, residual volume; SNIP, sniff nasal inspiratory pressure; TLC, total lung capacity.

experienced a mild reduction in the 6MWD by a mean of $41 \mathrm{~m}$ at 2,590 $\mathrm{m}$ and by $22 \mathrm{~m}$ at 1,650 $\mathrm{m}$. At 1,650 m, bicycle exercise tests revealed a mild reduction of maximal performance by $7 \%$ related to hypoxemia and ventilatory limitation. Over the course of the 4-day sojourn at higher altitude, 9 of the 38 patients (24\%) experienced symptoms of AMS, dyspnea, or severe hypoxemia that required oxygen therapy for safety reasons. The current results represent a valuable reference that might help to counsel COPD patients planning altitude travel and prevent adverse effects on their health.

Data on exercise performance of COPD patients traveling to altitude are scant. In a study by Kelly et al, ${ }^{14} 18$ COPD patients (mean $\mathrm{FEV}_{1} 42 \%$ predicted) were transported by car from sea level to Mt Hutt $(2,086 \mathrm{~m})$ for a sojourn of few hours. Not all patients were able to complete the 6-minute walk, and their mean walk distance was reduced to less than half of that at sea level (from 467 to $245 \mathrm{~m}$ ). In eight COPD patients $\left(\mathrm{FEV}_{1} 25 \%-78 \%\right.$ predicted) traveling from sea level to Mount Washington (1,920 m), Vermont, $\mathrm{PaO}_{2}$ initially dropped from 8.8 to $6.8 \mathrm{kPa}$, but values increased to $7.3 \mathrm{kPa}$ with acclimatization over 4 days; patients performed mild treadmill exercise without notable problems. ${ }^{15}$ In the Dutch Asthma Center Davos (1,560 m), 37 lowlanders with $\mathrm{COPD}\left(\mathrm{FEV}_{1} 63 \%\right.$ predicted) underwent a 5-week

Table 4 Arterial blood gases

\begin{tabular}{|c|c|c|c|c|}
\hline & $490 \mathrm{~m}$ & $\mathrm{I}, 650 \mathrm{~m}$ & $2,590 \mathrm{~m}$ & $P$-value \\
\hline $\mathrm{pH}$ & 7.4I (7.39; 7.42) & $7.44 *(7.42 ; 7.45)$ & $7.45^{* \dagger \dagger}(7.43 ; 7.46)$ & $<0.001$ \\
\hline $\mathrm{PaCO}_{2}, \mathrm{kPa}$ & $5.5(4.9 ; 5.9)$ & $5.0 *(4.7 ; 5.3)$ & $4.9 *(4.6 ; 5.2)$ & $<0.001$ \\
\hline $\mathrm{PaO}_{2}, \mathrm{kPa}$ & $9.0(8.4 ; 9.4)$ & $8 . I^{*}(7.5 ; 8.6)$ & $6.8^{*, \dagger}(6.3 ; 7.4)$ & $<0.001$ \\
\hline $\mathrm{SaO}_{2}, \%$ & $93(93 ; 95)$ & $91 *(89 ; 92)$ & $85^{*, \dagger}(84 ; 89)$ & $<0.001$ \\
\hline $\mathrm{HCO}_{3}^{-}, \mathrm{mmol} / \mathrm{L}$ & $25.9(24.5 ; 27.4)$ & $25.0(24.4 ; 25.5)$ & $25.6^{\dagger}(25.2 ; 26.8)$ & 0.006 \\
\hline Base excess, $\mathrm{mmol} / \mathrm{L}$ & $1.2(0.9 ; 2.1)$ & $0.7 *(0.1 ; 1.4)$ & $0.9(0.3 ; 1.8)$ & 0.037 \\
\hline $\mathrm{DAaPO}_{2},{ }^{25} \mathrm{kPa}$ & $4.5(3.9 ; 5.4)$ & $3.4 *(2.5 ; 3.9)$ & $3.1^{*, \dagger}(2.5 ; 3.4)$ & $<0.001$ \\
\hline Hemoglobin, g/dL & $15.0(|4.5 ;| 5.2)$ & $14.6(14.1 ; 15.2)$ & I4.8(I4.2; I5.5) & 0.066 \\
\hline Hematocrit, \% & $44.5(43.0 ; 44.8)$ & $43.0 *(41.0 ; 44.5)$ & $43.8^{\dagger}(42.0 ; 46.0)$ & 0.015 \\
\hline
\end{tabular}

Notes: Median (quartiles), $\mathrm{n}=32$. Arterial blood gases were drawn in the morning after the first night at the corresponding altitude. $P$-values computed by Friedman ANOVA for overall effects. $* P<0.05$ vs $490 \mathrm{~m}$ day I, ${ }^{\dagger} P<0.05$ vs $\mathrm{I}, 650 \mathrm{~m}$ day $\mathrm{I}$.

Abbreviation: $\mathrm{DAaPO}_{2}$, Alveolar-arterial $\mathrm{PO}_{2}$ difference. 
Table 5 Maximal exercise performance

\begin{tabular}{|c|c|c|}
\hline Values at peak exercise & $490 \mathrm{~m}$ & $\mathrm{I}, 650 \mathrm{~m}$ \\
\hline Time, min:sec & $9: 13(7: 45 ; 10: 50)$ & $8: 4 I^{*}(6: 46 ; 10: 38)$ \\
\hline Work rate, watts & $92(73 ; 120)$ & $82 *(63 ; 120)$ \\
\hline$\%$ predicted & $75(59 ; 94)$ & $69 *(59 ; 87)$ \\
\hline Heart rate, $1 / \mathrm{min}$ & $127(115 ; 138)$ & $123(115 ; 140)$ \\
\hline$\%$ predicted & $80(75 ; 88)$ & $80(75 ; 88)$ \\
\hline $\mathrm{V}^{\prime} \mathrm{O}_{2}, \mathrm{~L} / \mathrm{min}$ & $1.21(0.90 ; 1.43)$ & $1.06(0.88 ; 1.47)$ \\
\hline$\%$ predicted & $67(54 ; 85)$ & $63(52 ; 86)$ \\
\hline $\mathrm{V}^{\prime} \mathrm{O}_{2}, \mathrm{~mL} / \mathrm{min} / \mathrm{kg}$ & $15.9(\mid 4.2 ; 19.8)$ & $15.0 *(12.5 ; 19.7)$ \\
\hline$\%$ predicted & $78(6 I ; 85)$ & $65 *(55 ; 90)$ \\
\hline $\mathrm{V}^{\prime} \mathrm{CO}_{2}, \mathrm{~L} / \mathrm{min}$ & $1.23(0.90 ; 1.57)$ & $1.10(0.87 ; 1.54)$ \\
\hline$\%$ predicted & $43(37 ; 52)$ & $4 \mathrm{I}(29 ; 55)$ \\
\hline Respiratory exchange ratio & $1.03(0.93 ; 1.09)$ & $1.03(0.95 ; 1.12)$ \\
\hline Breath rate, L/min & $36(29 ; 40)$ & $36 *(32 ; 40)$ \\
\hline $\mathrm{V}^{\prime} \mathrm{E}, \mathrm{L} / \mathrm{min}$ & $52(40 ; 64)$ & $53^{*}(38 ; 66)$ \\
\hline $\mathrm{BR}, \%$ & $20(5 ; 30)$ & $\mid 2 *(-3 ; 2 \mid)$ \\
\hline $\mathrm{V}^{\prime} \mathrm{E} / \mathrm{VO}_{2}$ & $38.4(33.6 ; 45.2)$ & $42.0 *(37.0 ; 48.3)$ \\
\hline $\mathrm{V}^{\prime} \mathrm{E} / \mathrm{VCO}_{2}$ & $37.6(33.2 ; 43.8)$ & $41.0 *(36.8 ; 47.4)$ \\
\hline Pulse oximetry, $\%$ & 95 (88; 98) & $90 *(85 ; 95)$ \\
\hline Arterial $\mathrm{pH}$ & $7.37^{\#}(7.34 ; 7.39)$ & $7.40 *(7.35 ; 7.42)$ \\
\hline $\mathrm{PaCO}_{2}, \mathrm{kPa}$ & $5.4^{\#}(5.3 ; 5.8)$ & $4.7^{*}(4.4 ; 4.9)$ \\
\hline $\mathrm{PaO}_{2}, \mathrm{kPa}$ & 7.7" $(7.1 ; 9.7)$ & $7.5 *(6.5 ; 8.2)$ \\
\hline $\mathrm{SaO}_{2}, \%$ & $92^{\#}(88 ; 95)$ & $89 *(83 ; 90)$ \\
\hline $\mathrm{DAaPO}_{2},{ }^{25} \mathrm{kPa}$ & $5.5^{\#}(3.6 ; 6.1)$ & $3.7 *(3.1 ; 4.6)$ \\
\hline Borg CR-I0 dyspnea & $5(4 ; 7)$ & $5(4 ; 7)$ \\
\hline Borg CR-10 leg & $3(2 ; 5)$ & $3(1 ; 5)$ \\
\hline
\end{tabular}

Notes: Median (quartiles), $\mathrm{n}=3 \mathrm{I}$. Breathing reserve calculated by (MVV-V'E)/ $M V{ }^{*} 100 ; * P<0.05$ vs $490 \mathrm{~m}$; ${ }^{\# A r t e r i a l ~ b l o o d ~ g a s ~ a n a l y s i s ~ d u r i n g ~ m a x i m a l ~ e x e r c i s e ~}$ was available in 31 patients at $1,650 \mathrm{~m}$ and in 12 patients at $490 \mathrm{~m}$; changes in arterial blood gas between 490 and I,650 m are presented for the 12 patients.

Abbreviations: $\mathrm{BR}$, breathing reserve; $\mathrm{DAaPO}_{2}$, Alveolar-arterial $\mathrm{PO}_{2}$ difference; $\mathrm{MVV}$, maximal voluntary ventilation; $\mathrm{V}^{\prime} \mathrm{O}_{2}$, oxygen uptake; $\mathrm{V}^{\prime} \mathrm{CO}_{2}$, carbon dioxide output; $V^{\prime} E$, minute ventilation.

rehabilitation training. Compared with baseline evaluation at sea level, their exercise capacity at arrival at 1,560 $\mathrm{m}$ was not significantly reduced and it increased over the course of rehabilitation. ${ }^{16}$ No other studies on exercise performance during intermediate or long-term altitude sojourns of COPD patients were identified.

Compared with the patients reported by Kelly et al, ${ }^{14}$ the participants in the current trial had a less pronounced reduction in the 6MWD, which might be due to less severe COPD in the current trial $\left(\mathrm{FEV}_{1} 59 \%\right.$ vs $42 \%$ predicted). Another explanation is the difference in the study design because half of the patients in the current trial already stayed for 2 days at 1,650 $\mathrm{m}$ before ascending further to 2,590 $\mathrm{m}$ (Figure 1), which might have led to improved physical performance at 2,590 $\mathrm{m}$ by acclimatization.

We have previously reported a reduction of endurance time during submaximal cycle exercise by $54 \%$ in COPD patients at 2,590 m. ${ }^{4}$ Underlying mechanisms were combined effects of hypobaric hypoxia on dyspnea and pulmonary gas exchange with arterial and cerebral hypoxemia (measured by near-infrared spectroscopy), while ventilatory limitation seemed not to have played a predominant role. Because exercise intensity during a 6MWD is submaximal, we assume that similar mechanisms may have contributed to the impaired performance at higher altitudes compared with $490 \mathrm{~m}$ in COPD patients participating in the current study. In turn, during progressive maximal ramp exercise at $1,650 \mathrm{~m}$, our results suggest that mechanical ventilatory limitation has contributed to the reduction in maximal work performance. Thus, the breathing reserve was reduced, and there was a greater ventilatory inefficiency evidenced by the increased ventilatory equivalents for both $\mathrm{O}_{2}$ uptake and $\mathrm{CO}_{2}$ output (Table 3 ).

In the current patients, there were no relevant changes in static and dynamic lung volumes at 2,590 vs $490 \mathrm{~m}$ (Table 3). For comparison, previous studies in healthy individuals ${ }^{17}$ and in patients with obstructive sleep apnea syndrome ${ }^{18}$ ascending to 2,590 $\mathrm{m}$ have shown a slight reduction in FVC that was not associated with a change in inspiratory muscle strength and was therefore possibly related to subclinical interstitial fluid accumulation. In the current study, a larger interindividual variability of baseline lung function in the COPD patients may have reduced the power to detect minor, altitude-induced changes. However, the current patients having an already reduced diffusing capacity to nearly half of the predicted value at $490 \mathrm{~m}$ revealed a further decrease at 2,590 $\mathrm{m}$ (Table 3). This was associated with an increase in body weight, suggesting a possible interstitial pulmonary fluid accumulation as suspected in healthy individuals in previous studies. ${ }^{19,20}$

In addition to the impairment of pulmonary gas exchange and consecutive hypoxemia related to the airflow limitation and parenchymal destruction of the lung, a potential further cause of exercise limitation in COPD patients at altitude relates to an excessive rise in pulmonary artery pressure due to hypoxic vasoconstriction in the presence of some degree of preexisting pulmonary hypertension. In support of this hypothesis, echocardiographic studies performed at rest revealed an elevated pulmonary artery pressure at 2,590 m compared with that at $490 \mathrm{~m} .^{21}$

In this trial, 9 of the 38 randomized patients (24\%) ascending to higher altitude suffered from adverse altituderelated health effects including headaches and clinically relevant symptoms of AMS $(5 \%$ at $1,650 \mathrm{~m}, 18 \%$ at $2,590 \mathrm{~m}$ ), and $13 \%$ had severe hypoxemia at 2,590 $\mathrm{m}$ that prompted us to administer supplemental oxygen. While symptoms of AMS might have been controlled by pain 
suppressants and other drugs including acetazolamide or dexamethasone that are successfully used in healthy mountaineers suffering from AMS, ${ }^{22}$ we considered it unethical to expose the COPD patients to prolonged hypoxemia with $\mathrm{SpO}_{2}<80 \%$. The rules for administration of oxygen were arbitrary because there is no conclusive evidence to suggest that level and duration of hypoxemia represent an increased risk for COPD patients, some of them with cardiovascular comorbidities. It is conceivable, however, that the risk for relevant cardiac arrhythmias and possibly adverse cardiovascular events might have been elevated at 2,590 $\mathrm{m}$ because we have previously observed a prolongation of the QT interval in patients with COPD during a stay at $2,048 \mathrm{~m}^{23}$ or with obstructive sleep apnea syndrome at 2,590 m..${ }^{24}$ Moreover, we suspect that those COPD patients who had severe hypoxemia would have developed more severe symptoms of AMS if they had stayed untreated at altitude for a longer time.

According to our study design, the order of exposure to the different altitudes was performed in random order to reduce the bias that might have been induced by a fixed sequence of stay at the three elevations. The fact that half of the patients had already spent 2 days at a higher altitude than that of their residence before assessments at 1,650 or $2,590 \mathrm{~m}$, respectively (Figure 1), is a limitation that might have influenced the incidence of AMS and other altitude-related adverse health effects by acclimatization. In particular, we cannot exclude that a direct ascent from $490 \mathrm{~m}$ to $2,590 \mathrm{~m}$ by all participants might have resulted in a higher incidence of AMS and other adverse outcomes. However, in multivariable regression analysis, the altitude exposure sequence was not an independent predictor of the 6MWD. Although a relatively large number of well-characterized COPD patients participated in the current study, it included patients with moderate to severe COPD only; therefore, our results might not apply to patients with very severe $\left(\mathrm{FEV}_{1}<30 \%\right.$ predicted) or only mild $\left(\mathrm{FEV}_{1}>80 \%\right.$ predicted) COPD.

\section{Conclusion}

The results of the current study demonstrate that lowlanders with moderate to severe COPD experience a modest decrease in the 6MWD when ascending for 2 days to $1,650 \mathrm{~m}$ and $2,590 \mathrm{~m}$ and their maximal performance during bicycle exercise is decreased at $1,650 \mathrm{~m}$ due to hypoxemia and ventilatory limitation. Severe hypoxemia for prolonged time was prevented by oxygen administration. Therefore, more severe impairments and adverse health effects might have been avoided. Our data may serve as a valuable basis for counseling patients with COPD planning altitude travel taking the individual condition, the physical fitness, and comorbidities into account.

\section{Acknowledgments}

This study has been supported by grants of the Swiss National Science Foundation and Zurich Lung League. Siemens Healthcare Diagnostics GmbH, Zurich, Switzerland, provided the blood gas analyzer and some equipment.

\section{Author contributions}

MF, DF, TDL, and KEB contributed to study design, data collection, analysis and drafting, or critically revising the manuscript. PMS, SDS, SM-M, CM, and AS contributed to data collection, analysis, and took part in revising the manuscript. SU, TR, and MK contributed to study design, data analysis, and took part in revising the manuscript. All authors gave final approval of the version to be published; and agree to be accountable for all aspects of the work.

\section{Disclosure}

SU reports grants from Swiss National Science Foundation, Zurich Lung League, grants and personal fees from Actelion SA, OrPha Swiss, personal fees from MSD, outside the submitted work. MK reports personal fees from Boehringer Ingelheim, Novartis, CSL Behring, Mundipharma grants, and personal fees from Roche, AstraZeneca, and Bayer outside the submitted work. The other authors report no conflicts of interest in this work.

\section{References}

1. Global Initiative for Chronic Obstructive Lung Disease. Global strategy for diagnosis, management, and prevention of chronic obstructive pulmonary disease. GOLD; 2017. Available from: https://goldcopd.org/ download/326/. Accessed August 28, 2018.

2. Tourism statistics - intra-EU tourism flows 2017. Available from: http://ec.europa.eu/eurostat/statistics-explained/index.php/ Tourism_statistics_-_intra-EU_tourism_flows. Accessed May 2, 2018.

3. Meier D, Collet TH, Locatelli I, et al. Does this patient have acute mountain sickness? The rational clinical examination systematic review. JAMA. 2017;318(18):1810-1819.

4. Furian M, Hartmann SE, Latshang TD, et al. Exercise performance of lowlanders with COPD at 2,590 m: data from a randomized trial. Respiration. 2018;95(6):422-432.

5. ATS statement, ATS Committee on Proficiency Standards for Clinical Pulmonary Function Laboratories, Statement ATS. ATS statement: guidelines for the six-minute walk test. Am J Respir Crit Care Med. 2002; 166(1):111-117.

6. American Thoracic Society/European Respiratory Society. ATS/ERS Statement on respiratory muscle testing. Am J Respir Crit Care Med. 2002;166(4):518-624.

7. Miller MR, Hankinson J, Brusasco V, et al. Standardisation of spirometry. Eur Respir J. 2005;26(2):319-338. 
8. Macintyre N, Crapo RO, Viegi G, et al. Standardisation of the single-breath determination of carbon monoxide uptake in the lung. Eur Respir J. 2005;26(4):720-735.

9. American Thoracic Society, American College of Chest Physicians. ATS/ACCP Statement on cardiopulmonary exercise testing. Am J Respir Crit Care Med. 2003;167(2):211-277.

10. Borg E, Kaijser L. A comparison between three rating scales for perceived exertion and two different work tests. Scand J Med Sci Sports. 2006;16(1):57-69.

11. Mahler DA, Wells CK. Evaluation of clinical methods for rating dyspnea. Chest. 1988;93(3):580-586.

12. Sampson JB, Cymerman A, Burse RL, Maher JT, Rock PB. Procedures for the measurement of acute mountain sickness. Aviat Space Environ Med. 1983;54(12 Pt 1):1063-1073.

13. Puhan MA, Mador MJ, Held U, Goldstein R, Guyatt GH, Schünemann HJ. Interpretation of treatment changes in 6-minute walk distance in patients with COPD. Eur Respir J. 2008;32(3):637-643.

14. Kelly PT, Swanney MP, Stanton JD, Frampton C, Peters MJ, Beckert LE. Resting and exercise response to altitude in patients with chronic obstructive pulmonary disease. Aviat Space Environ Med. 2009;80(2): 102-107.

15. Graham WG, Houston CS. Short-term adaptation to moderate altitude. Patients with chronic obstructive pulmonary disease. JAMA. 1978; 240(14):1491-1494.

16. Bijl D, Speelberg B, Folgering HT. Pulmonary rehabilitation at moderate altitude: a 1-year follow-up. Neth J Med. 1994;45(4):154-161.

17. Latshang TD, Lo Cascio CM, Stöwhas A-C, et al. Are nocturnal breathing, sleep, and cognitive performance impaired at moderate altitude (1,630-2,590 m)? Sleep. 2013;36(12):1969-1976.
18. Latshang TD, Nussbaumer-Ochsner Y, Henn RM, et al. Effect of acetazolamide and autoCPAP therapy on breathing disturbances among patients with obstructive sleep apnea syndrome who travel to altitude: a randomized controlled trial. JAMA. 2012;308(22):2390-2398.

19. Clarenbach CF, Senn O, Christ AL, Fischler M, Maggiorini M, Bloch KE. Lung function and breathing pattern in subjects developing high altitude pulmonary edema. PLoS One. 2012;7(7):e41188.

20. Senn O, Clarenbach CF, Fischler M, et al. Do changes in lung function predict high-altitude pulmonary edema at an early stage? Med Sci Sports Exerc. 2006;38(9):1565-1570.

21. Lichtblau M, Latshang T, Furian M, et al. Right and left ventricular function in lowlanders with COPD travelling to moderate altitude. Eur Respir J. 2015;46(Suppl 59):PA3756.

22. Luks AM, Mcintosh SE, Grissom CK, et al. Wilderness Medical Society practice guidelines for the prevention and treatment of acute altitude illness: 2014 update. Wilderness Environ Med. 2014;25(4 Suppl): S4-S14.

23. Bisang M, Latshang TD, Furian M, et al. P156 Risk of cardiac arrhythmias in lowlanders with COPD travelling to high altitude. Randomized trial of nocturnal oxygen therapy. Chest. 2017;151(5):A54.

24. Latshang TD, Kaufmann B, Nussbaumer-Ochsner Y, et al. Patients with obstructive sleep apnea have cardiac repolarization disturbances when travelling to altitude: randomized, placebo-controlled trial of acetazolamide. Sleep. 2016;39(9):1631-1637.

25. Crapo RO, Jensen RL, Hegewald M, Tashkin DP. Arterial blood gas reference values for sea level and an altitude of 1,400 meters. Am J Respir Crit Care Med. 1999;160(5 Pt 1):1525-1531.
International Journal of COPD

\section{Publish your work in this journal}

The International Journal of COPD is an international, peer-reviewed journal of therapeutics and pharmacology focusing on concise rapid reporting of clinical studies and reviews in COPD. Special focus is given to the pathophysiological processes underlying the disease, intervention programs, patient focused education, and self management protocols.

\section{Dovepress}

This journal is indexed on PubMed Central, MedLine and CAS. The manuscript management system is completely online and includes a very quick and fair peer-review system, which is all easy to use. Visit $\mathrm{http}: / /$ www.dovepress.com/testimonials.php to read real quotes from published authors. 